\title{
Thermography in vascular disorders affecting the brain
}

\author{
MAURICE GROSS' AND MARY POPHAM \\ From the National Hospital for Nervous Diseases, Queen Square, Lon lon
}

Increasing interest in the field of cerebrovascular disease has resulted in a demand for diagnostic procedures free from risk which can be used for screening purposes to decide which cases should be further investigated. Thermography, which combines a high degree of accuracy with complete safety, meets the need. The first reports of the value of this method (Wood, 1965; Wood, Hill, and Heyman, 1965) have received recent confirmation (Mawdsley, Samuel, Sumerling, and Young, 1968) which is extended by the present report.

Thermography involves the detection of heat energy by an infra-red sensitive device, with subsequent conversion to electrical energy, amplification, and a suitable means of display. As the heat emitted from the skin is related to blood flow, measurement of the heat emission gives a measure of blood flow. The main application of thermography to cerebrovascular disease is made possible by the fact that, whereas the skin of the face is mainly perfused by branches of the external carotid artery, there is an area in the medial supraorbital region which is nearly always supplied by the terminal branches of the ophthalmic artery, which derives directly from the internal carotid artery immediately distal to the cavernous portion (Fig. 1). It follows therefore that a lesion of the internal carotid artery between its origin in the neck and the origin of the ophthalmic artery is liable to produce a reduced blood flow in the medial supraorbital skin, which will be detectable thermographically as a cool area (Fig. 2). A normal thermogram is shown for comparison (Fig. 3).

\section{MATERIALS AND METHOD}

The instrument used in this survey is the Pyroscan made by Smith's Medical Equipment Company. The infra-red detector is an indium antimonide crystal which when refrigerated by liquid nitrogen is sensitive to wavelengths from approximately 1.5 to $5.5 \mu$. The infra-red radiation emitted by the subject is focused by a scanning mirror on to the detector. The electrical conductivity of the

${ }^{1}$ Requests for reprints should be addressed to M.G. detector varies according to the incident infra-red radiation. The change in conductance is converted into a voltage which is amplified, and a facsimile is built up line by line on to electro-chemically impregnated recording paper. The whole process takes between one half and one minute, and the finished record can be described as a thermal map, delineated from black to white through varying shades of grey, corresponding to maximum and minimum output voltage and the various values in between. About 10 shades are distinguishable, and since the total temperature range approaches $10^{\circ} \mathrm{C}$ the picture can be read to about $1^{\circ} \mathrm{C}$. The machine can if necessary be adjusted to reduce the total range by more than half, thus allowing temperature differentiation of approximately $0.5^{\circ} \mathrm{C}$. The room containing the Pyroscan is kept at a temperature of $16^{\circ} \mathrm{C}$, the optimum ambient temperature at which the machine works. The patient is taken into this cool room and the skin temperature is allowed to equilibrate for approximately 20 minutes, by which time rapid cooling of the skin will no longer be taking place and differences in temperature from one part of the face to another are clearly die to local differences

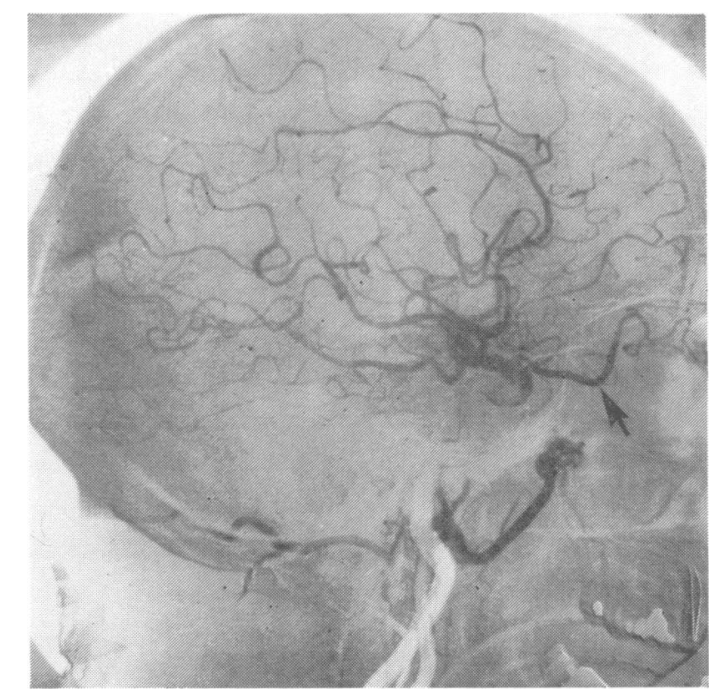

FIG. 1. Subtraction photograph of carotid angiogram showing normal ophthalmic artery (arrowzd). 


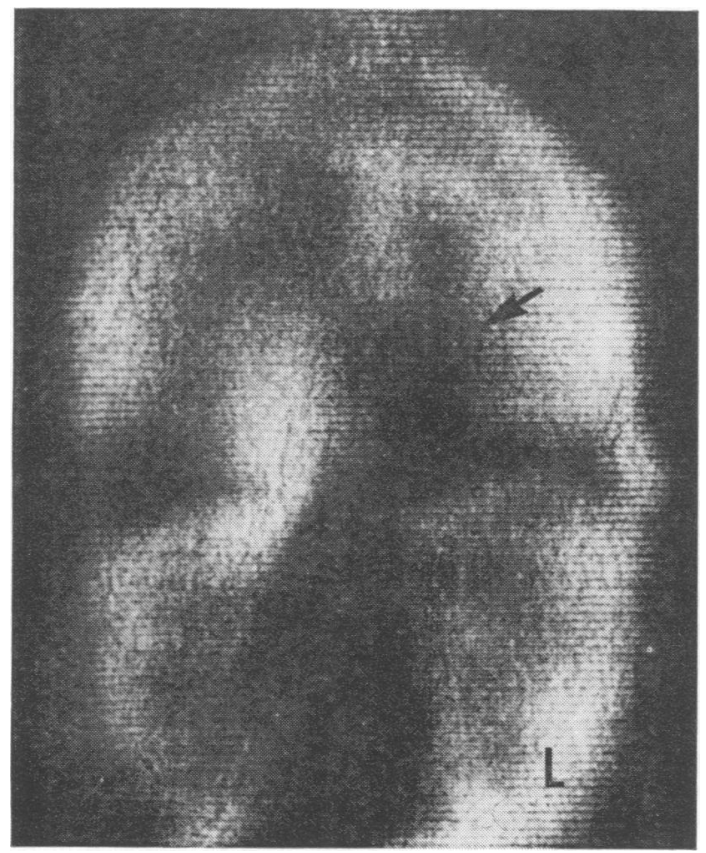

FIG. 2. Thermogram of patient with left internal carotid occlusion, showing cool patch in left supraorbital region (arrowed) and increased warmth due to collateral circulation in contralateral orbit and supraorbital area (N.B. dark $=$ cool, light $=$ warm).

in infra-red emissivity, rather than artefactually related to the relatively slow speed of scanning and high skin cooling rates.

THE PATIENTS Seventy-six subjects were referred for thermography because it was suspected or known that they were suffering from vascular disorders affecting the intra or extracranial cerebral circulation. Arteriography was done in all the cases, confirming the presence or indicating the absence of structural disease in the vascular territory under suspicion.

\section{RESULTS}

In order to achieve the maximum freedom from observer bias the thermographic records were reviewed by one of us (M.G.) without reference to the clinical data, 76 facial thermograms being viewed in this way. The records were divided into three categories-normal, abnormal, and equivocal -and the results were then correlated with the angiographic findings, only subjects in whom there was angiographic confirmation being included in the series. There were 31 subjects in whom the carotid tree had been shown to be normal either

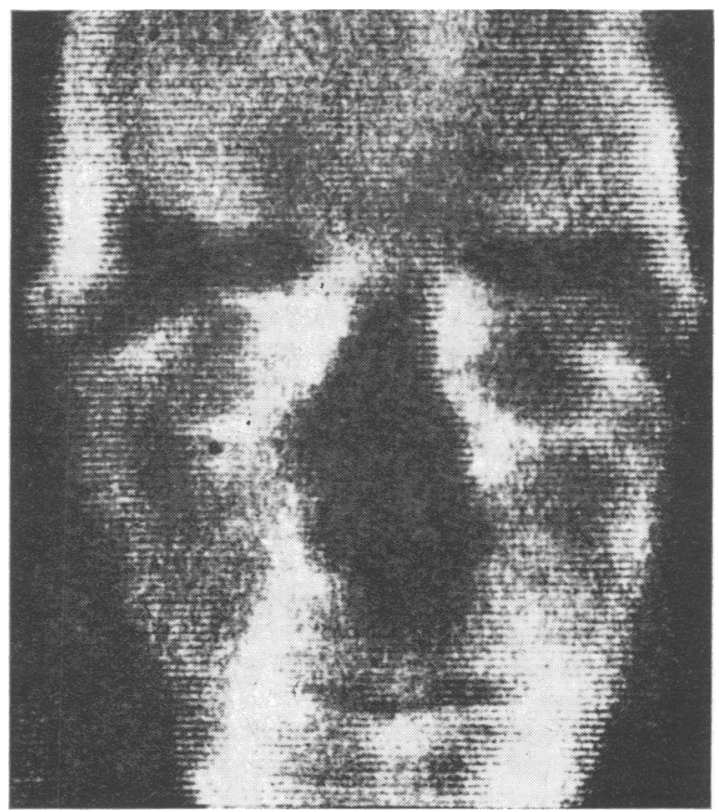

FIG. 3. Normal thermogram. Note the cool insulated hairy areas (eyebrows), cool nose, cheeks and sclerae. Symmetrically warm areas of medial parts of orbits, perinasal and periorbital regions.

on one side (unilateral carotid puncture, 20 cases) or both sides (aortic arch angiography, 11 cases). Twenty-eight of the 31 had normal thermograms, two were abnormal, and one was equivocal (Table I).

In 15 instances the angiograms (by unilateral carotid puncture in 10 cases and by aortic arch angiography in five) revealed a unilateral carotid occlusion (complete obstruction of the lumen). Of these, 10 were thermographically abnormal, the side of the lesion being correct in all 10 cases. There were three equivocal thermograms and two were normal.

TABLE I

THERMOGRAPHIC RESULTS RELATED TO ANGIOGRAPHY

\begin{tabular}{lcccc}
\hline \multicolumn{1}{c}{ Angiogram } & Normal & $\begin{array}{c}\text { Thermogram } \\
\text { Equivocal }\end{array}$ & Abnormal & Total \\
\hline $\begin{array}{c}\text { Unilateral internal } \\
\text { carotid occlusion } \\
\begin{array}{c}\text { Unilateral internal } \\
\text { carotid stenosis }\end{array}\end{array}$ & 2 & 3 & 10 & 15 \\
$\begin{array}{c}\text { Unilateral internal } \\
\text { carotid normal }\end{array}$ & 0 & 2 & 10 & 12 \\
$\begin{array}{c}\text { Middle cerebral } \\
\text { angiomatous malformation }\end{array}$ & 0 & 0 & 2 & 31 \\
\hline Totals & 30 & 6 & 26 & 62 \\
\hline
\end{tabular}


In 12 instances the angiograms showed unilateral carotid stenosis (by unilateral carotid puncture in seven and by aortic arch angiography in five), the thermogram being abnormal on the correct side in 10 and equivocal in two.

In four instances the angiogram showed a large angiomatous malformation in the territory of the middle cerebral artery. The thermographic appearances were abnormal in all, but differed from those of internal carotid artery obstruction in that the cool area was far more extensive, involving the whole forehead area on the side ipsilateral to the lesion (Fig. 4). The right carotid angiogram from the case illustrated in Fig. 4 is also shown (Fig. 5).

Thus, taking the abnormal and equivocal thermograms together, the success rate for diagnosing unilateral carotid occlusion thermographically was 13 out of a possible $15(87 \%)$, and for carotid stenosis 12 out of $12(100 \%)$. For unilateral carotid disease as a whole, therefore, 25 out of 27 were correctly diagnosed thermographically $(93 \%)$. An angiographically normal carotid tree was associated with a normal thermogram in 28 out of 31 patients $(90 \%)$.

Turning now to those cases in which there was angiographically bilateral disease of the internal carotid artery (Table II), there were four cases of

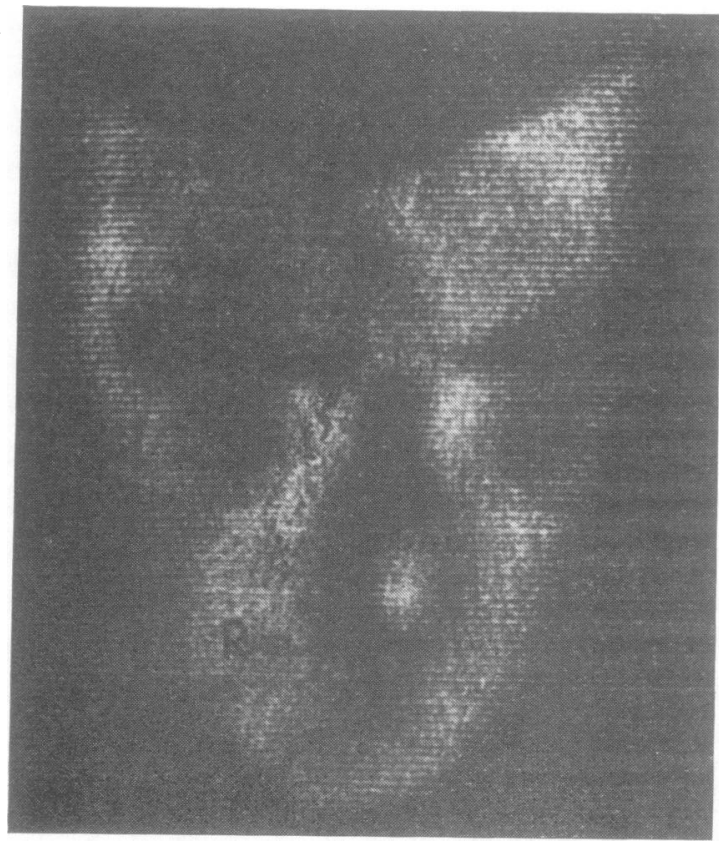

FIG. 4. Thermogram of patient with large right middle cerebral angiomatous malformation. The entire right forehead is cool.

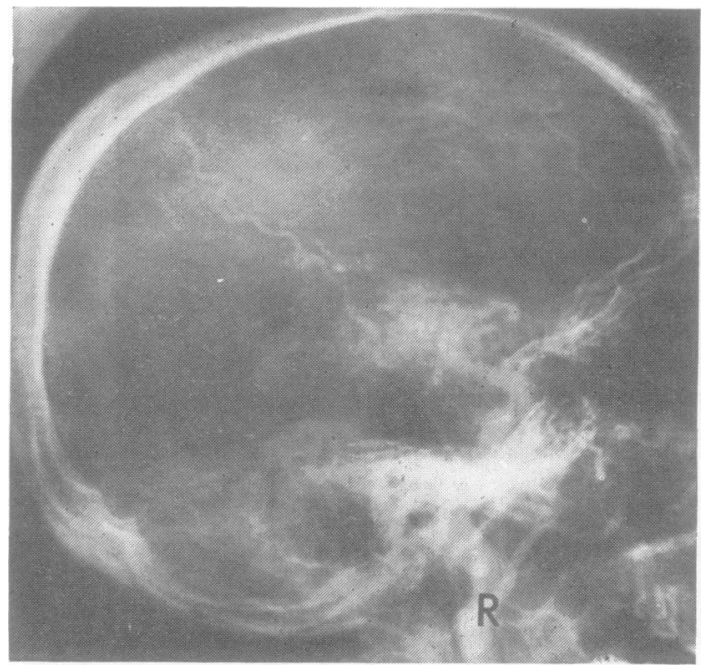

FIG. 5. Right carotid angiogram of patient depicted in Fig. 4, showing extensive angiomatous malformation at the origin of the middle cerebral artery.

complete bilateral internal carotid occlusion. In two of these the thermogram confirmed bilateral abnormalities, while two indicated a unilateral abnormality. Of the five cases of bilateral internal carotid stenosis, three were thermographically abnormal on one side only, one was equivocal, and one normal.

There were five cases in which angiography demonstrated occlusion of the internal carotid artery on one side and stenosis on the other. Of these, two had bilaterally abnormal thermograms, one was equivocal, and two were normal.

Thus out of a total of 14 cases of bilateral internal carotid artery disease, 11 were thermographically abnormal or equivocal and three were normal, giving a diagnostic success rate of $79 \%$.

To summarize, in this series, the thermograms failed to show significant internal carotid artery disease in five out of 41 cases in which it existed, and mistakenly suggested internal carotid artery disease

TABLE II

THERMOGRAPHIC RESULTS IN SUBJECTS WITH BILATERAL INTERNAL CAROTID DISEASE

\begin{tabular}{lccccc}
\hline \multicolumn{1}{c}{ Angiogram } & Normal & Equivocal & $\begin{array}{l}\text { Thermogram } \\
\text { Unilateral } \\
\text { abnormal }\end{array}$ & $\begin{array}{l}\text { Bilateral } \\
\text { abnormal }\end{array}$ & Total \\
\hline Bilateral occlusion & 0 & 0 & 2 & 2 & 4 \\
Bilateral stenosis & 1 & 1 & 3 & 0 & 5 \\
Unilateral occlusion/ & 2 & 1 & 0 & 2 & 5 \\
Contralateral stenosis & 2 & 2 & 5 & 4 & 14 \\
\hline Totals & 3 & & & &
\end{tabular}


in two out of 31 subjects with normal angiograms. The overall diagnostic accuracy of thermography therefore was $91 \%$, and the accuracy in diagnosing stenotic or occlusive disease in an internal carotid tree was $88 \%$.

POST-ENDARTERECTOMY REVIEW So far we have examined seven patients thermographically after endarterectomy on a stenosed internal carotid artery. Of these, four had normal thermograms, two still had abnormal thermograms, and one had an equivocal thermogram showing little change. The two cases with persistently abnormal thermograms post-endarterectomy both had clinically successful operations with re-establishment of flow at operation and pulsatile arteries (for what that is worth) in the neck at the time of thermography. Both have remained symptomless after operation but further angiography has not been done.

VERTEBROBASILAR ISCHAEMIA In view of the difficulty which may be found in distinguishing clinically between carotid ischaemia and vertebrobasilar ischaemia, the thermograms of 18 patients who had been referred with a definite diagnosis of infarction or ischaemic attacks in the vertebrobasilar distribution were reviewed. Of these 16 were normal. In two the thermographic diagnosis was left carotid obstruction, but arch angiography was normal in one of these and angiography not done in the other. In the 16 cases which were thermographically normal, five had normal arch angiograms, one had an abnormally small right vertebral artery, one had right subclavian and vertebral stenosis with left vertebral stenosis, and nine did not have angiography.

\section{DISCUSSION}

From the results, thermography clearly earns a place in the diagnostic armamentarium of cerebral vascular disorders. Leaving aside for the moment the less common conditions such as angioma, thermography can certainly provide a safe and useful addition to the investigations currently available in the diagnosis of obstructive disease of the carotid system. The results leave no doubt that the supraorbital heat pattern is abnormal in a very high proportion of cases of carotid stenosis or occlusion, and it is significant that in every case in which unilateral carotid disease was diagnosed correctly, there was no discrepancy about which side was affected.

It is important to consider those cases of proven carotid obstruction in which thermography failed to provide a positive answer; firstly one must empha- size that thermography will be of use in detecting carotid disease only when this is of such a degree as to impair the flow in the ipsilateral supraorbital artery-in other words, a complete occlusion or severe stenosis must be present before the facial heat pattern will change. It has been demonstrated that the cross-sectional area of an acutely stenosed carotid artery has to be very severely reduced, leaving a lumen of between 2 and 5 sq. mm (Brice, Dowsett, and Lowe, 1964) before the blood flow across the stenosis is reduced; this implies that a considerable number of cases of stenosis of lesser degree are likely to be missed by any method of diagnosis which depends on assessment of the blood flow distal to the obstruction. Lesser degrees of obstruction are, of course, still capable of producing neurological symptoms even when the flow is not reduced, by providing the site for embolus formation. Taking this into consideration, it is rather surprising that thermography should have been of positive value so frequently.

The other possible reason why a certain number of cases of stenosis or occlusion of the internal carotid system can be missed by thermography may be related to the finding that occasionally the main arterial supply to the orbit is not from the ophthalmic artery but from the so-called accessory ophthalmic artery which arises from the middle meningeal branch of the external carotid system (Gillilan, 1961). Alternatively, there may be a very adequate anastomosis in the orbit between the ophthalmic and accessory ophthalmic arteries, sufficient to provide a normal blood flow in the supraorbital region.

It is significant that three of the cases of proven carotid obstruction missed thermographically were cases in which both internal carotid arteries were shown by angiography to be diseased. It is not difficult to understand why this should be so, as we are concerned with the detection of differences of heat pattern on the two sides of the forehead, and bilateral, as opposed to unilateral carotid disease, tends to abolish this differential. Theoretically, one should be able to detect 'bilateral supraorbital coolness' and indeed it is sometimes possible to do this (Fig. 6), but in practice the thermographic appearance may suggest unilateral disease (Fig. 7). Difficulties of this sort were also encountered by Wood (1965) who commented on the paradoxical heat pattern which could be found in bilateral carotid disease, where the cooler supraorbital area was found on the side of the stenosis rather than the occlusion. The haemodynamic reasons for this are obscure, and in this series we came across this situation on only one occasion, in a subject diagnosed as 'equivocal' thermographically, whose heat pattern suggested possible right carotid obstruction but who 


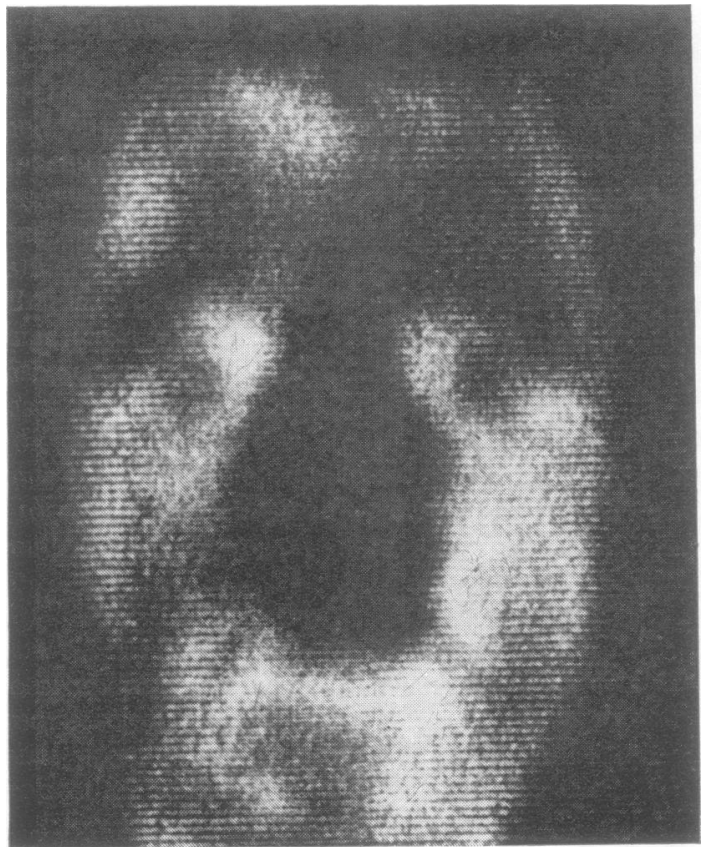

FIG. 6. Thermogram of patient with bilateral internal carotid occlusion. Note the excessive coolness in both supraorbital regions.

in fact had right internal carotid stenosis and left common carotid occlusion. Two cases were correctly diagnosed as bilateral carotid obstruction; in one there was bilateral internal carotid occlusion and in the other right internal carotid occlusion and left carotid stenosis.

Apart from obstructive lesions of the internal carotid system, other lesions are occasionally demonstrable thermographically. We have mentioned four cases in which a large intracerebral arteriovenous malformation in the middle cerebral territory produced an asymmetrical thermal pattern on the forehead. In both cases the entire forehead on the side ipsilateral to the lesion was markedly cooler than the contralateral side (Fig. 4). The reason for this is not quite clear, but it seems likely that this represents a 'steal' phenomenon whereby the high intracerebral blood flows through the malformation siphon off a large amount of the external carotid artery circulation on the side of the lesion, leaving the ipsilateral forehead and cheek detectably cooler.

Vertebrobasilar ischaemia does not appear to produce characteristic thermal changes on the face, and in the group of patients referred for examination with this diagnosis all were thought to be normal except two, in one of whom arch angiography was

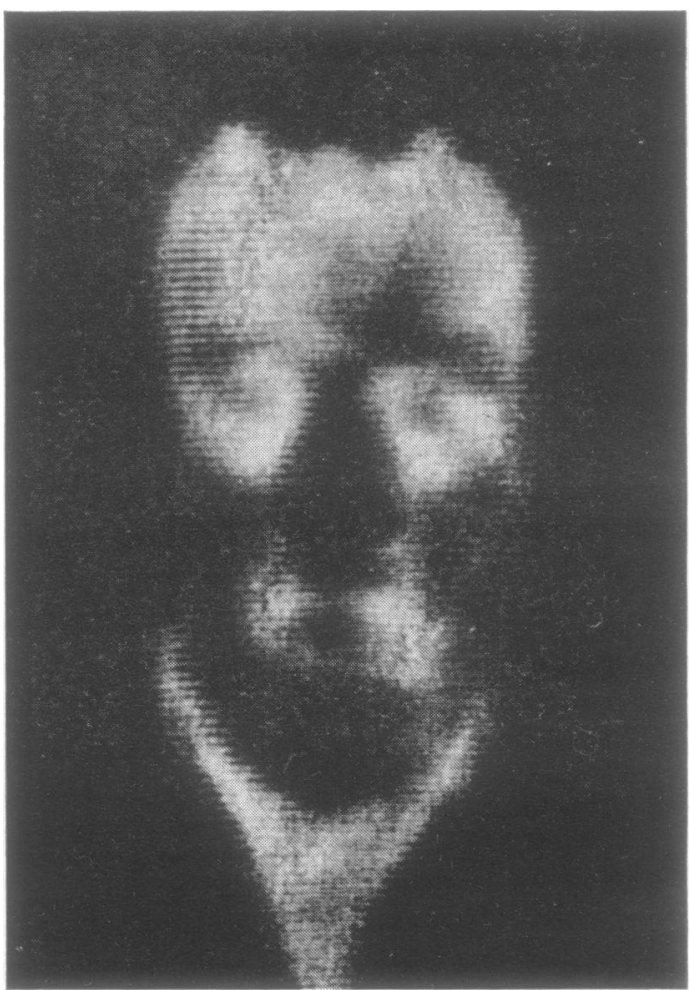

FIG. 7. Thermogram of a patient with bilateral internal carotid occlusion, in whom the appearances suggest only a left carotid occlusion.

negative but in the other no angiography was done. Thermography therefore has nothing to offer directly in the diagnosis of hind brain ischaemia, but since severe disease in the carotid system may present with transient ischaemic attacks in the vertebrobasilar territory it can nevertheless be rewarding.

\section{SUMMARY}

A survey of facial thermograms in 76 subjects in whom there was angiographic confirmation of the presence or absence of lesions affecting the carotid circulation has shown that this technique offers considerable accuracy in the diagnosis of unilateral internal carotid stenosis or occlusion.

Diagnosis of bilateral internal carotid arterial lesions was less accurate, the usual findings being the appearances of a unilateral lesion only, or a normal thermogram.

A review of all the thermograms of patients referred with a clinical diagnosis of vertebrobasilar ischaemia showed that abnormal thermal patterns 
are not seen in this condition. Thermography therefore has nothing to offer in the confirmation of vertebrobasilar ischaemia.

On four occasions intracranial angiomatous malformations in the middle cerebral artery territory have been detectable thermographically.

It is suggested that thermography is a valuable adjunct in screening for carotid disease in subjects with indefinitely localized cerebrovascular disease, and a useful confirmation in subjects suspected of having obstructive carotid artery disease. Its main use would therefore seem to be as an entirely safe screening procedure to select patients on whom it is worth taking the risks of angiography.
We wish to thank Dr. John Marshall and Dr. J. W. D. Bull for their help and guidance in the preparation of this paper, and also the Department of Medical Photography at the National Hospital, Queen Square.

\section{REFERENCES}

Brice, J. G., Dowsett, D. J., and Lowe, R. D. (1964). Haemodynamic effects of carotid artery stenosis. Brit. med.J., 2, 1363-1366.

Gillilan, L. (1961). The collateral circulation of the human orbit. Arch. Ophthal., 65, 684-694.

Mawdsley, C., Samuel, E., Sumerling, M. D., and Young, G. B. (1968). Thermography in occlusive cerebrovascular diseases. Brit. med. J., 3, 521-524.

Wood, E. H. (1965). Thermography in the diagnosis of cerebrovascular disease. Radiology, 85, 270-283.

- -, Hill, R., and Heyman, A. (1965). Diagnostic value of thermography in extracranial carotid occlusive disease. Trans. Amer. neurol. Ass., 90, 124-127.

\section{The August 1969 Issue}

\section{THE AUGUST 1969 ISSUE CONTAINS THE FOLLOWING PAPERS}

Cortical blindness and the functions of the non-geniculate fibres of the optic tracts G. S. BRINDLEY, P. C. GAUTIERSMITH, and W. LEWIN

Pure torsional nystagmus as a consequence of head trauma T. D. SABIN and J. A. POCHE

Vascular compression of the optic nerves relieved by anastomosis of carotid artery to jugular vein KEVIN BLEASEL and JOAN FREW

Congenital muscular dystrophy: light and electron microscopic observations A. AFIFI, H. ZELLWEGER, W. F. MCCORMICK, and W. MERGNER

Experimental studies related to autoimmunity in myasthenia gravis B. M. KAUFMAN, G. RUSHWORTH, and R. WRIGHT

Treatment of myasthenia gravis with adrenocorticotropic hormone (ACTH): massive short-term and maintenance treatment CHARLES A. CAPE and ROBERT A. UTTERBACK

Vincristine neuropathy: an electrophysiological and histological study J. G. MCLEOD and R. PENNY

Brain tumour and pregnancy JOST J. MICHELSEN and PAUL F. J. NEW

Fistula between three main cerebral arteries and a large occipital vein J. BRET and $z$. KUNC

Intracranial Hodgkin's disease shown by radioisotope scan s. CURRIE and G. W. H. JARDINE
Histochemical changes in neocortex and corpus callosum after intracranial injection N. ROBINSON

Lactate dehydrogenase and glutamic oxalacetic transaminase of the cerebrospinal fluid in tumours of the central nervous system G. A. B. DAVIES-JONES

Spongy degeneration in the white matter of the central nervous system in the newborn: pathological findings in three infants, one with hyperglycinaemia JOHN $M$. ANDERSON

Encephalitis with myoclonous in Whipple's disease N. STOUPEL, G. MONSEU, A. PARDOU, R. HEIMANN, and J. J. MARTIN

Addison's disease and diffuse cerebral sclerosis ANNE $\mathbf{M}$. GRAY

Electron microscopy of giant-cell (temporal) arteritis KENNETH R. SMITH, Jr.

Motor and sensory conduction in different segments of the radial nerve in normal subjects W. TROJABORG and E. H. SINDRUP

Metastatic cerebellar abscess producing nerve deafness CHRISTOPHER GARDNER-THORPE and S. T. AL-MUFTI

Book Reviews

Copies are still available and may be obtained from the PUBLISHING MANAGER, BRITISH MEDICAL ASSOCIATION, TAVISTOCK SQUARE, W.C.1, price $21 \mathrm{~s}$. 